\title{
MRI/PET Imaging in elevated PSA and localized prostate cancer: a narrative review
}

\author{
Subodh K. Regmi ${ }^{1}$, Niranjan Sathianathen ${ }^{2}$, Thomas E. Stout ${ }^{1}$, Badrinath R. Konety ${ }^{3}$ \\ ${ }^{1}$ Department of Urology, University of Minnesota, Minneapolis, MN, USA; ${ }^{2}$ Department of Urology, University of Melbourne, Melbourne, \\ Australia; ${ }^{3}$ Rush Medical College, Chicago, IL, USA \\ Contributions: (I) Conception and design: BR Konety, SK Regmi; (II) Administrative support: BR Konety, SK Regmi; (III) Provision of study materials \\ or patients: SK Regmi, N Sathianathen, TE Stout; (IV) Collection and assembly of data: SK Regmi, N Sathianathen, TE Stout; (V) Data analysis and \\ interpretation: All authors; (VI) Manuscript writing: All authors; (VII) Final approval of manuscript: All authors. \\ Correspondence to: Subodh K. Regmi. Department of Urology, University of Minnesota, Minneapolis, MN, 55455, USA. Email: regmi014@umn.edu.
}

\begin{abstract}
Objective: To review the recent milestones in MRI and PET based imaging and evaluate their evolving role in the setting of elevated PSA as well as localized prostate cancer.

Background: The importance of multiparametric MRI (mpMRI) and PET based imaging for the diagnosis and staging of prostate cancer cannot be understated. Accurate staging has become another significant milestone with the use of PET scans, particularly with prostate specific radiotracers like 68-Gallium Prostate Specific Membrane Antigen (68Ga-PSMA). Integrated PET/MRI systems are commercially available and can be modulated to evaluate the unique needs of localized as well as recurrent prostate cancer.

Methods: A literature search was performed using PubMed and Google Scholar using the MeSH compliant and other keywords that included prostate cancer, PSA, mpMRI, PET CT, PET/MRI.

Conclusions: mpMRI has now established itself as the gold-standard of local prostate imaging and has been incorporated into international guidelines as part of the diagnostic work-up of prostate cancer. PSMA PET/CT has shown superiority over conventional imaging even in staging of localized prostate cancer based on recent randomized control data. Imaging parameters from PET/MRI have been shown to be associated with malignancy, Gleason score and tumour volume. As mpMRI and PSMA PET/CT become more ubiquitous and established; we can anticipate more high-quality data, cost optimization and increasing availability of PET/MRI to be ready for primetime in localized prostate cancer.
\end{abstract}

Keywords: Prostate cancer; PSA; mpMRI; PET CT; PET/MRI

Submitted Apr 28, 2021. Accepted for publication Jun 09, 2021.

doi: $10.21037 /$ tau-21-374

View this article at: https://dx.doi.org/10.21037/tau-21-374

\section{Introduction}

The role of newer imaging modalities for diagnosis and staging of prostate cancer cannot be understated. Their importance lies not only in the ability to accurately identify clinically significant cancer but also in the improved diagnostic predictability, which can help avoid unnecessary biopsies. Accurate staging has become another significant milestone with the use of PET scans, particularly with prostate specific radiotracers like PSMA. An enhanced ability to potentially identify oligo-metastatic disease has led to newer treatment paradigms and fueled further research into multimodality management of these patients (1).

Multiparametric MRI (mpMRI) improves the

^ ORCID: 0000-0001-5940-6302. 
identification and detection of clinically significant prostate cancer in biopsy naïve patients as well as those with prior negative biopsies (2). Prostate Imaging Reporting and Data System version 2 (PI-RADS v2) (3), initially developed with a multinational consensus based process, has been updated to the recent PI-RADS v2.1 (4) to improve reproducibility between the readers. This has greatly improved the accuracy of MRI reporting and MRI targeted biopsies in academic as well as community settings (2). Additional roles have emerged in risk stratification for potential biopsies when combined with PSA density, substantially increasing the yield of clinically significant prostate cancer (2). The use of mpMRI as part of a predictive nomogram has also been proposed and is awaiting further external validation (1).

PET utilizes various radiotracers and has been on the forefront of cancer imaging in view of its combined functional and morphological value with cross sectional imaging with CT. $11 \mathrm{C}$-choline and $18 \mathrm{~F}$-FACBC (fluciclovine) are two tracers that are currently FDA approved in the US for evaluation of biochemically recurrent disease whereas in other parts of the world, 68Ga-PSMA has been more routinely employed in clinical practice (5). Recent evidence has shown that the use of PSMA PET CT can significantly impact clinical decision making (6) or even result in treatment change (7).

PET/MRI was developed with the intent of improving on the weaknesses of existing PET /CT systems (8). Over the years this evolution itself, which was late to start, currently boasts of a variety of advantages that have been primarily attributed to the incorporation of the MRI platform (9). PET/MRI started with the concept of isochronous fusion of PET and MRI technologies postulating benefits in brain as well as oncological imaging (8). In localized prostate cancer, initial reports utilized parametric fusion of separately acquired PET and MRI images (10) which later paved way for the use of less cumbersome hybrid scanners.

The ongoing use and development of several prostate specific PET radiotracers has also fueled this progress. Recent strong recommendations for the use of multi parametric MRI (mpMRI) prior to prostate biopsy (2) and the promising results from PSMA PET trials (11) have paved way for further substantiative research. As standardized protocols and optimal radiotracers are being developed for prostate cancer diagnosis and staging, it is necessary to evaluate the current role and future prospects of these modalities. The following review is presented in accordance with the Narrative Review reporting checklist (available at https://dx.doi.org/10.21037/tau-21-374).

\section{Methods}

A literature search was performed using PubMed and Google Scholar using the MeSH compliant and other keywords that included prostate cancer, PSA, mpMRI, PET CT, PET/MRI. All authors reviewed relevant published literature until 2021 March for inclusion in this narrative review.

\section{mpMRI for localized prostate cancer}

mpMRI has now established itself as the gold-standard of local prostate imaging. The PROMIS study of 576 men undergoing mpMRI prior to biopsy reported that mpMRI was significantly more sensitive at detecting clinically significant prostate cancer than transrectal ultrasound guided biopsy ( $93 \%$ vs. $48 \%, \mathrm{P}<0.01$ ) (12). A recently published meta-analysis of 7,321 men found that the negative predictive value of $\mathrm{mpMRI}$ for the detection of clinically significant disease was $87-97 \%$ depending on the definitions set for "positive" MRI and "clinically significant cancer" (13). The high diagnostic performance of MRI has seen it being incorporated into international guidelines as part of the diagnostic work-up of prostate cancer. The European Association of Urology (EAU) guidelines make a level 1a, strong recommendation to perform an mpMRI prior to prostate biopsy (2). Furthermore, there is a level $2 \mathrm{a}$, weak recommendation to omit biopsy when the mpMRI is negative and the clinical suspicion of disease is low. Although the data for mpMRI is impressive, it is not a perfect test (14) The accuracy of mpMRI is highly dependent on the experience of the radiologists interpreting it. In a study of 409 men with an elevated PSA who underwent an mpMRI, Sonn et al. reported that there was marked variation in PIRADS scores and cancer detection amongst nine radiologists in an academic centre (15). The challenge, in one study, was the individual cancer detection rates for radiologists in PIRADS 3 lesions (16). Even for PIRADS 4 and 5 lesions the cancer detection rate spanned 
across a broad range of $23-65 \%$ and $40-80 \%$, respectively. The area under the receiver operating characteristic curve ranged from 0.69 to 0.81 for the detection of significant prostate cancer amongst the radiologists involved int the study. Additional factors such as the magnetic field, the use of an endorectal coil and assessment system have all been shown to influence the performance of mpMRI (17). Moreover, there is a subgroup of prostate cancer that are 'invisible' on mpMRI and are missed when only targeted biopsies are taken. Radtke et. al showed that biopsy of targeted cores only missed up to $12.8 \%$ Gleason 7 or more cancers (18). Therefore, clinicians cannot be entirely reliant on mpMRI to make decisions on clinical prostate cancer and need to incorporate other tools into the process.

\section{PET/CT: current status}

Positron emission tomography (PET) has been extensively used for whole-body staging of cancers to evaluate metastatic spread. PET tracers such as 68-Gallium Prostate Specific Membrane Antigen (68Ga-PSMA) has superseded conventional staging modalities such as bone scintigraphy and computer tomography (CT) for prostate cancer in many centres globally $(5,19)$. The success of using PET imaging in the secondary staging settings has encouraged their use earlier in the disease process to primary staging of prostate cancer. There are several retrospective studies that have demonstrated the potential of PET in staging of primary prostate cancer.

\section{Tracers in prostate cancer}

Many different PET radiotracers have been investigated for use in $\mathrm{CaP}$, and some of those have been used for PET/ MRI. The goal of diagnostic functional imaging with PET is to use tracers that selectively target components of $\mathrm{CaP}$ cells in vivo. There is also ongoing work regarding the use of PET-directed theranostics in $\mathrm{CaP}$ patients, however that is outside the scope of this review. The various PET tracers investigated for their use in $\mathrm{CaP}$ are outlined below.

\section{Fluorodeoxyglucose (FDG)}

FDG, a glucose analog, is taken up by glucose transporters and sequestered in cells as FDG-6-phosphatase (20). While most cancers have upregulated glucose metabolism making FDG a useful tracer, $\mathrm{CaP}$ has relatively lower glucose metabolism and instead uses alternative metabolic pathways such as fructose and fatty acids $(21,22)$. Additionally, FDG has low utility in the detection of localized prostate cancer due to difficulties resulting from urinary excretion and uptake sometimes seen in $\mathrm{BPH}$ or prostatitis (23). For these reasons FDG PET is rarely used in prostate cancer.

\section{${ }^{11}$ C-Choline}

This membrane phospholipid is internalized by the enzyme choline kinase, which is overexpressed in $\mathrm{CaP}$ and was the first PET radiotracer approved for CaP by the FDA (24). Choline PET has been shown to have superior detection rates for pelvic lymph nodes in patients undergoing radical prostatectomy, with a sensitivity and specificity upwards of $70 \%$ and $90 \%$, respectively $(25,26)$. As is the case with FDG, the role of choline PET in the localization of primary prostate cancer is limited due to multiple false positives. Other choline-based tracers including ${ }^{18} \mathrm{~F}$-fluoroethylcholine and ${ }^{18} \mathrm{~F}$-fluoromethylcholine have been studied. While ${ }^{18} \mathrm{~F}$ isotopes have the benefits of longer half-lives thereby negating the need for an onsite cyclotron, their use has been limited significantly due to urinary excretion, which obfuscates the prostatic bed and periprostatic tissues. There have been relatively few studies of ${ }^{11} \mathrm{C}$ and ${ }^{18} \mathrm{~F}$ choline PET/MRIs in $\mathrm{CaP}$, which have shown promise in terms of improved accuracy per lesion as well as per patient in the PET/MRI model as compared to the mpMRI model only (27-30).

\section{${ }^{18}$ F-Fluciclovine $\left(\right.$ Axumin $^{\circledR}$ )}

As amino acid synthesis and transportation is upregulated in $\mathrm{CaP}$ cells, the amino acid analogue ${ }^{18} \mathrm{~F}$-fluciclovine has been shown to be a viable PET tracer. ${ }^{18} \mathrm{~F}$-fluciclovine PET, or Axumin, was FDA approved in 2016 for the use in recurrent $\mathrm{CaP}$. Benefits of Axumin include minimal renal excretion or bladder uptake and a longer half-life compared to ${ }^{11} \mathrm{C}$ choline (31). Axumin has a limited role in evaluating primary prostate lesions. While it does not outperform MRI, the combination of Axumin PET and 
MRI has a superior PPV for tumor localization (82\%) than either modality alone $(32,33)$. The value of Axumin in initial staging is also unclear, as one multicenter study demonstrated similar lymph node detection rates (85.5$87.3 \%$ ) compared to CT but a higher detection rate of small bone metastases $(91.6 \%)$ compared to traditional scintigraphy (61.1\%) (34). The primary role of Axumin PET is detecting $\mathrm{CaP}$ recurrence either in the prostate bed or elsewhere. PET/MRI with ${ }^{18} \mathrm{~F}$-Fluciclovine has been investigated for $\mathrm{CaP}$, both for primary nodal staging and to evaluate response to ADT (35-37). In one single center prospective study of 14 patients with high risk $\mathrm{CaP}$ and negative conventional imaging, Axumin PET/MRI detected lymph node metastases in seven patients. Of the 10 patients in this cohort treated with $\mathrm{ADT}$ and radiation, all demonstrated interval decrease in tracer activity within the primary lesion after ADT (37).

\section{Prostate-specific membrane antigen (PSMA)}

To date the most studied tracer for PET/MRI is PSMA. This membrane glycoprotein is expressed in the prostate and highly upregulated in prostate cancer $(38,39)$. While the enzyme is found in other tissues including salivary glands, renal tubules, and non-genitourinary malignant blood vessels, PSMA expression in $\mathrm{CaP}$ is $100-1000 \times$ higher comparatively $(40,41)$. Unlike PSA, PSMA also continues to be expressed in cancers that are androgen-deprived (42). The most common ligand used for PSMA PET is ${ }^{68} \mathrm{Ga}$ PSMA-HBED-CC, primarily due to its ease of synthesis. Alternative ligands including PSMA-inhibitor and ${ }^{18} \mathrm{~F}$ have been investigated, but data are limited (43).

While most studies of PSMA PET have focused in recurrent and advanced disease, there has been some work investigating primary tumor localization and staging. The sensitivity and specificity of PSMA PET in detecting clinically significant prostate lesions is similar to that of MRI, and simultaneous PSMA PET/MRI outperforms either modality alone $(44,45)$. PET/MRI studies using PSMA significantly outnumber those using alternative PET tracers, and are described in the next section.

Greater tracer uptake has been seen in Grade Group 2 two or higher cancers and in those with PSA $>10$, indicating usefulness in identifying high risk disease (46). PSMA PET appears to outperform conventional imaging when staging patients with primary $\mathrm{CaP}$. In one study of 130 patients with intermediate- or high-risk $\mathrm{CaP}$ the accuracy of nodal staging using a templated lymph node dissection as the reference was $89 \%$ for PSMA PET vs. $72 \%$ for CT (47). PSMA also outperforms bone scans in the detection of bone metastases with sensitivities and specificities of $99-100 \%$ and $88-100 \%$, respectively (48).

However, only recently have randomized data been available to support the superiority of PSMA PET over conventional staging in this setting. The proPSMA study was a randomised, cross-over study where 302 men with high-risk localized prostate cancer underwent primary staging with conventional imaging and gallium-68 PSMA11 PET-CT. The study found that the latter modality was $27 \%$ more accurate than CT and bone scanning (11). The reported sensitivity and specificity of PSMA PET/ CT in this trial was $85 \%$ and $98 \%$, respectively, which was significantly higher than conventional imaging. It was also found that PSMA PET/CT changed management more often than CT and bone scan. This study has entrenched the superiority of PSMA PET/CT.

\section{The rationale for PET/MRI}

The proposed benefit of PET/MRI in localized prostate cancer is based on our current limited ability to accurately diagnose and stage patients, and perhaps also on the necessity to perform multiple distinct imaging tests with inherent fallacies. Conventional staging modalities have limited ability to accurately stage lymph nodes and can even miss bony metastases $(12,49,50)$ including in high risk disease with low osteoblastic activity $(51) .{ }^{18} \mathrm{~F}-\mathrm{NaF}$ PET/ CT can detect bony metastasis better but are less specific and therefore, not recommended for initial staging by either the AUA or EUA $(2,50)$. The promise of PET/MRI lies in its ability to combine the soft tissue detail inherent to MRI with the functional imaging of PET using CaPspecific tracers. It also adds value due to the incorporation of diffusion weighted imaging (DWI), better motion correction and the increased available time to collect PET data (9). However, standardized study protocols of these 
complex imaging modalities are still being optimized and higher cost and limited installations prohibit widespread usage (9).

\section{PET/MRI basics and image acquisition}

PET/MRI imaging systems can be either in tandem or integrated. Tandem systems have the MRI and PET machines located either in adjacent rooms or side-by-side in the same room with a moveable patient table between (52,53). Tandem PET/MRI units such as the Phillips Ingenuity (Phillips Healthcare, Cleveland, USA) were the initial systems developed because the magnetic field generated by the MRI machine did not interfere with the PET unit. Due to the large footprint and cumbersome nature of tandem PET/MRIs, these have largely been supplanted by their integrated counterparts. A major hurdle of integrated or simultaneous systems is the fact that the photomultiplier tubes used in traditional PET scanners cannot function within a strong magnetic field. The development of "avalanche" photodiodes, photon detectors insensitive to magnetic changes, was the breakthrough that allowed development of and commercialization of modern integrated PET/MRIs $(54,55)$. While one drawback of avalanche photodiodes is the inability to measure time of flight, silicon photomultiplier detectors have been developed to circumvent this limitation (56).

Two integrated PET/MRI systems are commercially available: The Siemens Biograph MR (Siemens Healthcare, Germany) and the GE Signa (General Electric Healthcare, Chicago, IL) $(55,57)$. Both models utilize a $60-\mathrm{cm}$ bore 3-T MR gantry. The Biograph MR utilizes avalanche photodiodes and places the PET detector between the body radiofrequency coil and gradient set. The GE system uses silicon photomultipliers instead of avalanche photodiodes and the PET component is between the radiofrequency shield of the body coil and the gradient coils (58). There is no standardized imaging protocol for PET/MRI, and each study should be tailored to the clinical scenario. As is the case with PET/CT, absorption and scatter due to photontissue interaction leads to attenuation and decreased signal reduction $(59,60)$. A variety of attenuation correction techniques may be employed and include bed and coil hardware attenuation correction, truncation correction, and patient attenuation correction (61). For the MR-portion of the exam, anatomic (T1, T2) and functional (DWI, DCE) sequences are obtained to assist in identifying lesions within the transition and peripheral zones, respectively. Protocols may also differ between patients with primary $\mathrm{CaP}$ or in those with concern for recurrence. In the former isotropic $\mathrm{T} 2$ sequences allow for assessment of neurovascular and seminal vesical invasion, while in the latter high-resolution axial T2 images allow to better evaluate the prostatic fossa (62). While endorectal coils are currently not used with integrated PETMRIs due to imaging interference and limited space, novel endorectal coils are being investigated (63).

The excellent results of MRI to image the prostate and PET for primary staging has naturally led to investigations into the possibility of combining these two modalities for potentially even better results. There have been several reports of PET/MRI being superior to mpMRI in detecting intra-prostatic lesions. In a study of 66 men with biopsy proven prostate cancer undergoing PET, mpMRI, and combined 68Ga-PSMA HBED-CC PET/MRI, it was found that the latter was superior to mpMRI (0.88 vs. 0.73) (64). Similarly, Hicks et al. performed a retrospective analysis of 32 men who underwent 68Ga-PSMA-11 PET/MRI prior to radical prostatectomy and reported that the regionspecific sensitivity of PET/MRI and mpMRI alone was $74 \%$ and 50\% compared to whole-mount histology (65). These findings were also seen in 22 men who were imaged with mpMRI and integrated 68Ga-PSMA-11 PET/MRI prior to prostatectomy where PET/MRI had a significantly greater area under the curve (AUC; $0.95 v s$. 0.68) (66). It should be noted that Al-Bayati and colleagues reported that the number of equivocal results were significantly lower in the PET/MRI group. This may have important clinical relevance in determining the need for biopsy in patients with equivocal MRI results. de Perrot and colleagues suggested that the benefit of PET/MRI compared to mpMRI is mainly in characterising peripheral zone lesions where the reported AUC was 0.89 (67). They hypothesised that the adenomatous hyperplasia in the transition zone interfered with the detection of hypermetabolic foci by PET/MR coregistration. Although PSMA has been the dominant tracer in PET imaging of prostate cancer (5), both $18 \mathrm{~F}$-choline 
PET/MRI and 18 F-FDG PET/MRI have exhibited high diagnostic performance in primary staging (68). In a study of 31 men who underwent both $18 \mathrm{~F}$-choline PET/MRI and 18 F-FDG PET/MRI followed by radical prostatectomy, it was reported that integrated PET/MRI imaging with either tracer performed better than combined interpretation of mpMRI and 18 F-FDG PET/CT (68).

Imaging parameters from PET/MRI have been shown to be associated with malignancy, Gleason score and tumour volume. Several studies have demonstrated that malignant tissue displays a higher uptake ratio on PET compared to benign tissue aiding differentiation between the two (64). Metabolic volumetric PET uptake volume product which is a metabolic burden index that is calculated by the product of the mean standardized uptake volume (SUV) and tumour volume within an MRI-matched lesion, was shown to be significantly associated with Gleason score (69). Some of these volumetric indices were also shown to be associated with perineural invasion, lymphovascular invasion, extracapsular extension and seminal vesicle invasion (69). The additional information provided by PET/MRI may assist clinicians in risk stratification and to make important clinical decisions such as which patients to biopsy, who is suitable for active surveillance and who requires radical treatment. A retrospective cohort study of 71 men who underwent prostatectomy and received a pre-operative 68Ga-PSMA-11 PET/CT beforehand demonstrated that lesion intensity was able to predict Gleason score, upgrading from biopsy to RP histopathology, pathological stage, positive surgical margins and progression free survival (70).

Eiber et al. (64) have shown that MRI/PET improved the detection of PCa lesions based on sextant based analysis of the prostatectomy specimen compared to mpMRI alone (AUC: 0.88 vs. $0.73 ; \mathrm{P}<0.001$ ). Similarly, other studies by Taneja et al. (71), and Jena et al. (72) have shown that dual phase differential assessment of PSMA uptake in combination with mpMRI significantly increased the accuracy of the PET/MRI to identify malignant lesions on pathology. At this point, mpMRI guided biopsies are the preferred and recommended option (2) but nevertheless, there is data to fuel further research in using it as a prebiopsy modality.

Existing relevant experience on the multi-faceted use of PET/MRI in prostate cancer is summarized in Table 1.

\section{Future directions}

In the context of localized prostate cancer, there are three distinct directions in which further research is headed with regards to PET/MRI. These include evaluation of newer radiotracers, PET/MRI guided prostate biopsies and planning and response assessment in focal as well as radiation treatment of localized prostate cancer (83) (Table 2). The newer radiotracers being investigated are [18F] DCFPyL (84), and 68Ga DOTA Bombesin (85). [18F] DCFPyL has the distinction of superior kinetics and is rapidly cleared from tissues whereas $68 \mathrm{Ga}$ DOTA Bombesin targets Gastrin-releasing peptide receptor proteins which are highly expressed in prostate cancer cells (86). Several trials have also been initiated to evaluate the usefulness of this multiparametric metabolic hybrid imaging modality (Table 2) in the prebiopsy setting. Perhaps the most intriguing ongoing research is the use of PET /MRI in guiding surgical as well as non-surgical options like HIFU, cryotherapy, high dose brachytherapy and even external beam radiotherapy (Table 2).

\section{Conclusions}

Multi parametric MRI clearly stands out on the basis of strong evidence for pre biopsy evaluation and the role of PSMA PET/CT as a staging modality in localized prostate cancer is rising. The advantage of PET/MRI lies in the fact that it combines two of these excellent imaging modalities and MRI offers better soft tissue definition than CT. Areas where we could see its emerging role would be in oligometastatic disease and high-risk disease where the ability to identify more lesions would have a significant impact on the treatment approach (83). PET/MRI, therefore, has promising implications in the diagnosis and staging of prostate cancer but needs further validation in terms of research and logistics to be of primetime use. 
Table 1 PET/MRI data based on prebiopsy diagnosis of clinically significant disease, local disease staging pre prostatectomy and detection of local or distant recurrence post primary therapy

\begin{tabular}{|c|c|c|c|c|c|}
\hline $\begin{array}{l}\text { Disease } \\
\text { setting }\end{array}$ & Authors & $\begin{array}{l}\text { Isotope } \\
\text { used }\end{array}$ & $\begin{array}{c}\text { No of } \\
\text { patients }\end{array}$ & $\begin{array}{l}\text { Study } \\
\text { purpose }\end{array}$ & Study results \\
\hline \multirow[t]{3}{*}{ Pre biopsy } & $\begin{array}{l}\text { Eiber } \\
\text { et al. (64) }\end{array}$ & $\begin{array}{l}\text { 68Ga- } \\
\text { PSMA-11 }\end{array}$ & 53 & $\begin{array}{l}\text { PET/MRI vs. } \\
\text { mpMRI }\end{array}$ & $\begin{array}{l}\text { PET/MRI improves diagnostic accuracy for PCa localization both } \\
\text { compared with mpMRI and with PET imaging alone }\end{array}$ \\
\hline & $\begin{array}{l}\text { Taneja } \\
\text { et al. (71) }\end{array}$ & $\begin{array}{l}\text { 68Ga- } \\
\text { PSMA-11 }\end{array}$ & 35 & PET/MRI & $\begin{array}{l}\text { Dual-phase PSMA uptake improves accuracy of classifying malignant } \\
\text { versus benign prostate lesions }\end{array}$ \\
\hline & $\begin{array}{l}\text { Davenport } \\
\text { et al. (29) }\end{array}$ & $\begin{array}{l}18 \mathrm{~F} \\
\text {-choline }\end{array}$ & 52 & $\begin{array}{l}\text { PET/MRI vs. } \\
\text { mpMRI }\end{array}$ & $\begin{array}{l}18 \mathrm{~F} \text {-choline } \mathrm{PET} / \mathrm{mpMRI} \text { improved the identification of significant } \\
\text { prostate cancer compared with mpMRI with improved risk stratification of } \\
\text { intermediate-risk mpMRI lesions }\end{array}$ \\
\hline \multirow[t]{4}{*}{$\begin{array}{l}\text { Disease } \\
\text { staging }\end{array}$} & $\begin{array}{l}\text { Lee } \\
\text { et al. (68) }\end{array}$ & $\begin{array}{l}18 \mathrm{~F} \\
\text {-choline }\end{array}$ & 30 & $\begin{array}{l}\text { Detection of } \\
\text { disease }\end{array}$ & $\begin{array}{l}\text { Simultaneous PET/MRI is better for the detection of cancer and MRI- } \\
\text { assisted metabolic volumetric parameters provide better characterization } \\
\text { of primary prostate cancers than conventional PET and MRI parameters }\end{array}$ \\
\hline & $\begin{array}{l}\text { Thalgott } \\
\text { et al. ( } 75)\end{array}$ & $\begin{array}{l}\text { 68Ga- } \\
\text { PSMA-11 }\end{array}$ & 102 & $\begin{array}{l}\text { Detection of } \\
\text { Disease }\end{array}$ & $\begin{array}{l}\mathrm{PET} / \mathrm{MRI} \text { performs at least equally for tumor and lymph node stage } \\
\text { prediction compared with nomograms in high-risk PCa patients }\end{array}$ \\
\hline & $\begin{array}{l}\text { Muehlematter } \\
\text { et al. (76) }\end{array}$ & $\begin{array}{l}\text { 68Ga- } \\
\text { PSMA-11 }\end{array}$ & 40 & $\begin{array}{l}\text { PET/MRI vs. } \\
\text { mpMRI }\end{array}$ & $\begin{array}{l}\mathrm{PET} / \mathrm{MRI} \text { and mpMRI perform similarly for local staging of intermediate- } \\
\text { to-high-risk prostate cancer. } 68 \mathrm{Ga}-\mathrm{PSMA}-11 \mathrm{PET} / \mathrm{MRI} \text { has higher } \\
\text { sensitivity but lower specificity than mpMRI }\end{array}$ \\
\hline & $\begin{array}{l}\text { Garcia } \\
\text { et al. (77) }\end{array}$ & $\begin{array}{l}18 \\
\text { F-choline }\end{array}$ & 31 & $\begin{array}{l}\text { Impact of } \\
\text { PET/MRI on } \\
\text { Treatment }\end{array}$ & $\begin{array}{l}\text { 18F-choline PET/MRI had a complementary role for the T staging, with } \\
\text { a high detection rate for nodal and distant metastasis. PET/MRI findings } \\
\text { helped avoid radical treatment in } 22.6 \% \text { of patients }\end{array}$ \\
\hline \multirow{3}{*}{$\begin{array}{l}\text { Detection } \\
\text { of } \\
\text { Recurrence }\end{array}$} & $\begin{array}{l}\text { Joshi } \\
\text { et al. (80) }\end{array}$ & $\begin{array}{l}\text { 68Ga- } \\
\text { PSMA } 11\end{array}$ & 30 & $\begin{array}{l}\text { PET/MRI vs. } \\
\text { Conventional } \\
\text { Imaging }\end{array}$ & $\begin{array}{l}\text { PSMA PET/MRI detected local and pelvic lesions more accurately than } \\
\text { conventional imaging }\end{array}$ \\
\hline & $\begin{array}{l}\text { García } \\
\text { et al. (81) }\end{array}$ & $\begin{array}{l}(18) \\
\text { F-Choline }\end{array}$ & 36 & $\begin{array}{l}\text { Detection of } \\
\text { recurrence }\end{array}$ & $\begin{array}{l}\text { 18F-Choline PET/MRI had a high detection rate for recurrence with rising } \\
\text { PSA levels }<1 \mathrm{ng} / \mathrm{ml} \text { after prostatectomy, and resulted in a better tailored } \\
\text { approach to treatment }\end{array}$ \\
\hline & $\begin{array}{l}\text { Gordon } \\
\text { et al. (82) }\end{array}$ & $\begin{array}{l}\text { 68Ga- } \\
\text { PSMA } 11\end{array}$ & 30 & $\begin{array}{l}\text { Cost } \\
\text { effectiveness }\end{array}$ & $\begin{array}{l}68 \text { Ga-PSMA PET/MRI appears to be cost-effective than usual care to } \\
\text { detect prostate cancer recurrence }\end{array}$ \\
\hline
\end{tabular}




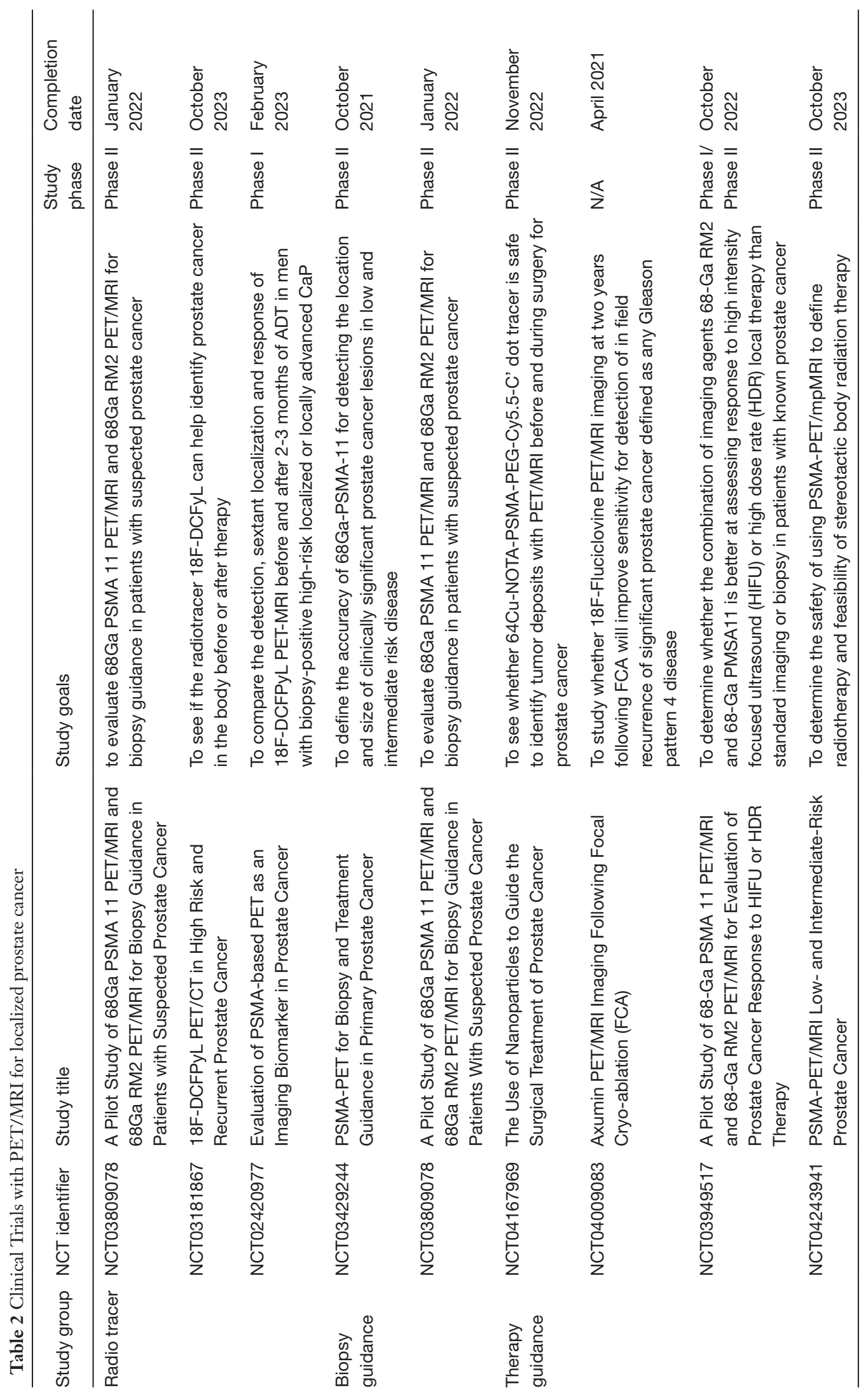




\section{Acknowledgments}

Funding: None.

\section{Footnote}

Provenance and Peer Review: This article was commissioned by the editorial office, Translational Andrology and Urology for the series "Current and Future Topics on Prostate Cancer". The article has undergone external peer review.

Reporting Checklist: The authors have completed the Narrative Review reporting checklist. Available at https:// dx.doi.org/10.21037/tau-21-374

Conflicts of Interest: All authors have completed the ICMJE uniform disclosure form (available at https://dx.doi. org/10.21037/tau-21-374). The series "Current and Future Topics on Prostate Cancer" was commissioned by the editorial office without any funding or sponsorship. BRK serves as an unpaid editorial board member of Translational Andrology and Urology and served as the unpaid Guest Editor of the series. The authors have no other conflicts of interest to declare.

Ethical Statement: The authors are accountable for all aspects of the work in ensuring that questions related to the accuracy or integrity of any part of the work are appropriately investigated and resolved.

Open Access Statement: This is an Open Access article distributed in accordance with the Creative Commons Attribution-NonCommercial-NoDerivs 4.0 International License (CC BY-NC-ND 4.0), which permits the noncommercial replication and distribution of the article with the strict proviso that no changes or edits are made and the original work is properly cited (including links to both the formal publication through the relevant DOI and the license). See: https://creativecommons.org/licenses/by-nc-nd/4.0/.

\section{References}

1. Schoots IG, Roobol MJ. Multivariate risk prediction tools including MRI for individualized biopsy decision in prostate cancer diagnosis: current status and future directions. World J Urol 2020;38:517-29.

2. Mottet N, van den Bergh RCN, Briers E, et al. EAUEANM-ESTRO-ESUR-SIOG Guidelines on Prostate
Cancer-2020 Update. Part 1: Screening, Diagnosis, and Local Treatment with Curative Intent. Eur Urol 2021;79:243-62.

3. Weinreb JC, Barentsz JO, Choyke PL, et al. PI-RADS Prostate Imaging - Reporting and Data System: 2015, Version 2. Eur Urol 2016;69:16-40.

4. Turkbey B, Rosenkrantz AB, Haider MA, et al. Prostate Imaging Reporting and Data System Version 2.1: 2019 Update of Prostate Imaging Reporting and Data System Version 2. Eur Urol 2019;76:340-51.

5. Sathianathen NJ, Butaney M, Konety BR, et al. The utility of PET-based imaging for prostate cancer biochemical recurrence: a systematic review and meta-analysis. World J Urol 2019;37:1239-49.

6. Perera M, Papa N, Christidis D, et al. Sensitivity, Specificity, and Predictors of Positive 68Ga-Prostatespecific Membrane Antigen Positron Emission Tomography in Advanced Prostate Cancer: A Systematic Review and Meta-analysis. Eur Urol 2016;70:926-37.

7. van Kalmthout LWM, van Melick HHE, Lavalaye J, et al. Prospective Validation of Gallium-68 Prostate Specific Membrane Antigen-Positron Emission Tomography/ Computerized Tomography for Primary Staging of Prostate Cancer. J Urol 2020;203:537-45.

8. Pichler BJ, Judenhofer MS, Pfannenberg C. Multimodal Imaging Approaches: PET/CT and PET/MRI BT Molecular Imaging I. In: Semmler W, Schwaiger M. editors. Berlin, Heidelberg: Springer Berlin Heidelberg, 2008:109-32.

9. Ehman EC, Johnson GB, Villanueva-Meyer JE, et al. PET/MRI: Where might it replace PET/CT? J Magn Reson Imaging 2017;46:1247-62.

10. Park H, Wood D, Hussain H, et al. Introducing parametric fusion PET/MRI of primary prostate cancer. J Nucl Med 2012;53:546-51.

11. Hofman MS, Lawrentschuk N, Francis RJ, et al. Prostatespecific membrane antigen PET-CT in patients with high-risk prostate cancer before curative-intent surgery or radiotherapy (proPSMA): a prospective, randomised, multicentre study. Lancet 2020;395:1208-16.

12. Ahmed HU, El-Shater Bosaily A, Brown LC, et al. Diagnostic accuracy of multi-parametric MRI and TRUS biopsy in prostate cancer (PROMIS): a paired validating confirmatory study. Lancet 2017;389:815-22.

13. Sathianathen NJ, Omer A, Harriss E, et al. Negative Predictive Value of Multiparametric Magnetic Resonance Imaging in the Detection of Clinically Significant Prostate Cancer in the Prostate Imaging Reporting and Data 
System Era: A Systematic Review and Meta-analysis. Eur Urol 2020;78:402-14.

14. Panebianco V, Giganti F, Kitzing YX, et al. An update of pitfalls in prostate mpMRI: a practical approach through the lens of PI-RADS v. 2 guidelines. Insights Imaging 2018;9:87-101.

15. Sonn GA, Fan RE, Ghanouni P, et al. Prostate Magnetic Resonance Imaging Interpretation Varies Substantially Across Radiologists. Eur Urol Focus 2019;5:592-9.

16. Sathianathen NJ, Warlick CA, Soubra A, et al. Difference in MRI-guided biopsy cancer detection rates between individual clinicians. Urol Oncol 2019;37:299.e1-6.

17. Stabile A, Giganti F, Kasivisvanathan V, et al. Factors Influencing Variability in the Performance of Multiparametric Magnetic Resonance Imaging in Detecting Clinically Significant Prostate Cancer: A Systematic Literature Review. Eur Urol Oncol 2020;3:145-67.

18. Radtke JP, Kuru TH, Boxler S, et al. Comparative analysis of transperineal template saturation prostate biopsy versus magnetic resonance imaging targeted biopsy with magnetic resonance imaging-ultrasound fusion guidance. J Urol 2015;193:87-94.

19. Maurer T, Eiber M, Fanti S, et al. Imaging for Prostate Cancer Recurrence. Eur Urol Focus 2016;2:139-50.

20. Macheda ML, Rogers S, Best JD, et al. Molecular and cellular regulation of glucose transporter (GLUT) proteins in cancer. J Cell Physiol 2005;202:654-62.

21. Reinicke K, Sotomayor P, Cisterna P, et al. Cellular distribution of Glut-1 and Glut-5 in benign and malignant human prostate tissue. J Cell Biochem 2012;113:553-62.

22. Liu Y, Zuckier LS, Ghesani NV, et al. Dominant uptake of fatty acid over glucose by prostate cells: a potential new diagnostic and therapeutic approach. Anticancer Res 2010;30:369-74.

23. Jadvar H. Is There Use for FDG-PET in Prostate Cancer? Semin Nucl Med 2016;46:502-6.

24. Contractor K, Challapalli A, Barwick T, et al. Use of [11C] choline PET-CT as a noninvasive method for detecting pelvic lymph node status from prostate cancer and relationship with choline kinase expression. Clin Cancer Res 2011;17:7673-83.

25. Mapelli P, Picchio M. Initial prostate cancer diagnosis and disease staging--the role of choline-PET-CT. Nat Rev Urol 2015;12:510-8.

26. Vag T, Heck MM, Beer AJ, et al. Preoperative lymph node staging in patients with primary prostate cancer: comparison and correlation of quantitative imaging parameters in diffusion-weighted imaging and 11C-choline PET/CT. Eur Radiol 2014;24:1821-6.

27. Piert M, Montgomery J, Kunju LP, et al. 18F-Choline PET/MRI: The Additional Value of PET for MRIGuided Transrectal Prostate Biopsies. J Nucl Med 2016;57:1065-70.

28. Tseng JR, Yang LY, Lin YC, et al. Metabolic Volumetric Parameters in 11C-Choline PET/MR Are Superior PET Imaging Biomarkers for Primary High-Risk Prostate Cancer. Contrast Media Mol Imaging 2018;2018:8945130.

29. Davenport MS, Montgomery JS, Kunju LP, et al. 18F-Choline PET/mpMRI for Detection of Clinically Significant Prostate Cancer: Part 1. Improved Risk Stratification for MRI-Guided Transrectal Prostate Biopsies. J Nucl Med 2020;61:337-43.

30. Riola-Parada C, Carreras-Delgado JL, Pérez-Dueñas V, et al. $18 \mathrm{~F}$-choline PET/MRI in suspected recurrence of prostate carcinoma. Rev Esp Med Nucl Imagen Mol (Engl Ed) 2018;37:296-301.

31. McParland BJ, Wall A, Johansson S, et al. The clinical safety, biodistribution and internal radiation dosimetry of $\left[{ }^{18} \mathrm{~F}\right]$ fluciclovine in healthy adult volunteers. Eur J Nucl Med Mol Imaging 2013;40:1256-64.

32. Parent EE, Schuster DM. Update on $18 \mathrm{~F}$-Fluciclovine PET for Prostate Cancer Imaging. J Nucl Med 2018;59:733-9.

33. Turkbey B, Mena E, Shih J, et al. Localized prostate cancer detection with 18F FACBC PET/CT: comparison with MR imaging and histopathologic analysis. Radiology 2014;270:849-56.

34. Suzuki H, Inoue Y, Fujimoto H, et al. Diagnostic performance and safety of NMK36 (trans-1-amino-3-[18F] fluorocyclobutanecarboxylic acid)-PET/CT in primary prostate cancer: multicenter Phase IIb clinical trial. Jpn J Clin Oncol 2016;46:152-62.

35. Elschot M, Selnæs KM, Sandsmark E, et al. Combined 18F-Fluciclovine PET/MRI Shows Potential for Detection and Characterization of High-Risk Prostate Cancer. J Nucl Med 2018;59:762-8.

36. Selnæs KM, Krüger-Stokke B, Elschot M, et al. 18F-Fluciclovine PET/MRI for preoperative lymph node staging in high-risk prostate cancer patients. Eur Radiol 2018;28:3151-9.

37. Galgano SJ, McDonald AM, Rais-Bahrami S, et al. Utility of 18F-Fluciclovine PET/MRI for Staging Newly Diagnosed High-Risk Prostate Cancer and Evaluating Response to Initial Androgen Deprivation Therapy: A Prospective Single-Arm Pilot Study. AJR Am J Roentgenol 
2021. doi: 10.2214/AJR.20.24509. [Epub ahead of print].

38. Davis MI, Bennett MJ, Thomas LM, et al. Crystal structure of prostate-specific membrane antigen, a tumor marker and peptidase. Proc Natl Acad Sci U S A 2005;102:5981-6.

39. Chang SS, Reuter VE, Heston WD, et al. Five different anti-prostate-specific membrane antigen (PSMA) antibodies confirm PSMA expression in tumor-associated neovasculature. Cancer Res 1999;59:3192-8.

40. Joshi A, Nicholson C, Rhee H, et al. Incidental Malignancies Identified During Staging for Prostate Cancer With 68Ga Prostate-specific Membrane Antigen HBED-CC Positron Emission Tomography Imaging. Urology 2017;104:e3-4.

41. Zhang AX, Murelli RP, Barinka C, et al. A remote arenebinding site on prostate specific membrane antigen revealed by antibody-recruiting small molecules. J Am Chem Soc 2010;132:12711-6.

42. Rajasekaran AK, Anilkumar G, Christiansen JJ, et al. Is prostate-specific membrane antigen a multifunctional protein? Am J Physiol Cell Physiol 2005;288:C975-81.

43. Cho SY, Gage KL, Mease RC, et al. Biodistribution, tumor detection, and radiation dosimetry of $18 \mathrm{~F}-\mathrm{DCFBC}$, a lowmolecular-weight inhibitor of prostate-specific membrane antigen, in patients with metastatic prostate cancer. J Nucl Med 2012;53:1883-91.

44. Giesel FL, Sterzing F, Schlemmer HP, et al. Intraindividual comparison of (68)Ga-PSMA-11-PET/CT and multi-parametric MR for imaging of primary prostate cancer. Eur J Nucl Med Mol Imaging 2016;43:1400-6.

45. Rhee H, Thomas P, Shepherd B, et al. Prostate Specific Membrane Antigen Positron Emission Tomography May Improve the Diagnostic Accuracy of Multiparametric Magnetic Resonance Imaging in Localized Prostate Cancer. J Urol 2016;196:1261-7.

46. Uprimny C, Kroiss AS, Decristoforo C, et al. 68GaPSMA-11 PET/CT in primary staging of prostate cancer: PSA and Gleason score predict the intensity of tracer accumulation in the primary tumour. Eur J Nucl Med Mol Imaging 2017;44:941-9.

47. Maurer T, Gschwend JE, Rauscher I, et al. Diagnostic Efficacy of (68)Gallium-PSMA Positron Emission Tomography Compared to Conventional Imaging for Lymph Node Staging of 130 Consecutive Patients with Intermediate to High Risk Prostate Cancer. J Urol 2016;195:1436-43.

48. Pyka T, Okamoto S, Dahlbender M, et al. Comparison of bone scintigraphy and 68Ga-PSMA PET for skeletal staging in prostate cancer. Eur J Nucl Med Mol Imaging 2016;43:2114-21.

49. Hövels AM, Heesakkers RA, Adang EM, et al. The diagnostic accuracy of CT and MRI in the staging of pelvic lymph nodes in patients with prostate cancer: a metaanalysis. Clin Radiol 2008;63:387-95.

50. Carter HB, Albertsen PC, Barry MJ, et al. American Urological Association (AUA) Guideline. Early detection of prostate cancer: AUA guideline. 2018. Available online: https://www.auanet.org/documents/Guidelines/PDF/Earl yProstateCancerGuideline_71318\%20PDF.pdf

51. Van den Wyngaert T, Strobel K, Kampen WU, et al. The EANM practice guidelines for bone scintigraphy. Eur J Nucl Med Mol Imaging 2016;43:1723-38.

52. Kuhn FP, Crook DW, Mader CE, et al. Discrimination and anatomical mapping of PET-positive lesions: comparison of CT attenuation-corrected PET images with coregistered MR and CT images in the abdomen. Eur J Nucl Med Mol Imaging 2013;40:44-51.

53. Zaidi H, Ojha N, Morich M, et al. Design and performance evaluation of a whole-body Ingenuity TF PET-MRI system. Phys Med Biol 2011;56:3091-106.

54. Pichler B, Lorenz E, Mirzoyan R, et al. Performance test of a LSO-APD PET module in a 9.4 Tesla magnet. In: 1997 IEEE Nuclear Science Symposium Conference Record. IEEE; 1997:1237-9.

55. Delso G, Fürst S, Jakoby B, et al. Performance measurements of the Siemens $\mathrm{mMR}$ integrated wholebody PET/MR scanner. J Nucl Med 2011;52:1914-22.

56. Yamamoto S, Watabe H, Kanai Y, et al. Interference between PET and MRI sub-systems in a siliconphotomultiplier-based PET/MRI system. Phys Med Biol 2011;56:4147-59.

57. Levin CS, Maramraju SH, Khalighi MM, et al. Design Features and Mutual Compatibility Studies of the Timeof-Flight PET Capable GE SIGNA PET/MR System. IEEE Trans Med Imaging 2016;35:1907-14.

58. Catana C. Principles of Simultaneous PET/MR Imaging. Magn Reson Imaging Clin N Am 2017;25:231-43.

59. Ziegler SL. Positron Emission Tomography: Principles, Technology, and Recent Developments. Nuclear Physics A 2005;752:679-87.

60. Keereman V, Mollet P, Berker Y, et al. Challenges and current methods for attenuation correction in PET/MR. MAGMA 2013;26:81-98.

61. Chen Y, An H. Attenuation Correction of PET/MR Imaging. Magn Reson Imaging Clin N Am 2017;25:245-55.

62. Souvatzoglou M, Eiber M, Martinez-Moeller A, et 
al. PET/MR in prostate cancer: technical aspects and potential diagnostic value. Eur J Nucl Med Mol Imaging 2013;40 Suppl 1:S79-88.

63. Choi CH, Felder T, Felder J, et al. Design, evaluation and comparison of endorectal coils for hybrid MR-PET imaging of the prostate. Phys Med Biol 2020;65:115005.

64. Eiber M, Weirich G, Holzapfel K, et al. Simultaneous 68Ga-PSMA HBED-CC PET/MRI Improves the Localization of Primary Prostate Cancer. Eur Urol 2016;70:829-36.

65. Hicks RM, Simko JP, Westphalen AC, et al. Diagnostic Accuracy of 68Ga-PSMA-11 PET/MRI Compared with Multiparametric MRI in the Detection of Prostate Cancer. Radiology 2018;289:730-7.

66. Al-Bayati M, Grueneisen J, Lütje S, et al. Integrated 68Gallium Labelled Prostate-Specific Membrane Antigen-11 Positron Emission Tomography/Magnetic Resonance Imaging Enhances Discriminatory Power of Multi-Parametric Prostate Magnetic Resonance Imaging. Urol Int 2018;100:164-71.

67. de Perrot T, Rager O, Scheffler M, et al. Potential of hybrid ${ }^{18} \mathrm{~F}$-fluorocholine PET/MRI for prostate cancer imaging. Eur J Nucl Med Mol Imaging 2014;41:1744-55.

68. Lee MS, Cho JY, Kim SY, et al. Diagnostic value of integrated PET/MRI for detection and localization of prostate cancer: Comparative study of multiparametric MRI and PET/CT. J Magn Reson Imaging 2017;45:597609.

69. Kim YI, Cheon GJ, Paeng JC, et al. Usefulness of MRIassisted metabolic volumetric parameters provided by simultaneous (18)F-fluorocholine PET/MRI for primary prostate cancer characterization. Eur J Nucl Med Mol Imaging 2015;42:1247-56.

70. Roberts MJ, Morton A, Donato P, et al. 68Ga-PSMA $\mathrm{PET} / \mathrm{CT}$ tumour intensity pre-operatively predicts adverse pathological outcomes and progression-free survival in localised prostate cancer. Eur J Nucl Med Mol Imaging 2021;48:477-82.

71. Taneja S, Jena A, Taneja R, et al. Effect of Combined 68Ga-PSMAHBED-CC Uptake Pattern and Multiparametric MRI Derived With Simultaneous PET/ MRI in the Diagnosis of Primary Prostate Cancer: Initial Experience. AJR Am J Roentgenol 2018;210:1338-45.

72. Jena A, Taneja R, Taneja S, et al. Improving Diagnosis of Primary Prostate Cancer With Combined 68Ga-ProstateSpecific Membrane Antigen-HBED-CC Simultaneous PET and Multiparametric MRI and Clinical Parameters. AJR Am J Roentgenol 2018;211:1246-53.
73. Ferraro DA, Becker AS, Kranzbühler B, et al. Diagnostic performance of 68Ga-PSMA-11 PET/MRI-guided biopsy in patients with suspected prostate cancer: a prospective single-center study. Eur J Nucl Med Mol Imaging 2021. doi: 10.1007/s00259-021-05261-y. [Epub ahead of print].

74. Freitag MT, Radtke JP, Hadaschik BA, et al. Comparison of hybrid (68)Ga-PSMA PET/MRI and (68)Ga-PSMA $\mathrm{PET} / \mathrm{CT}$ in the evaluation of lymph node and bone metastases of prostate cancer. Eur J Nucl Med Mol Imaging 2016;43:70-83.

75. Thalgott M, Düwel C, Rauscher I, et al. One-Stop-Shop Whole-Body 68Ga-PSMA-11 PET/MRI Compared with Clinical Nomograms for Preoperative T and N Staging of High-Risk Prostate Cancer. J Nucl Med 2018;59:1850-6.

76. Muehlematter UJ, Burger IA, Becker AS, et al. Diagnostic Accuracy of Multiparametric MRI versus 68Ga-PSMA-11 PET/MRI for Extracapsular Extension and Seminal Vesicle Invasion in Patients with Prostate Cancer. Radiology 2019;293:350-8.

77. Garcia JR, Compte A, Galan C, et al. 18F-choline PET/ MRI on initial staging of prostate cancer. Impact on therapy approach. Rev Esp Med Nucl Imagen Mol (Engl Ed) 2021;40:72-81.

78. Lütje S, Cohnen J, Gomez B, et al. Integrated 68GaHBED-CC-PSMA-PET/MRI in patients with suspected recurrent prostate cancer. Nuklearmedizin 2017;56:73-81.

79. Kranzbühler B, Nagel H, Becker AS, et al. Clinical performance of 68Ga-PSMA-11 PET/MRI for the detection of recurrent prostate cancer following radical prostatectomy. Eur J Nucl Med Mol Imaging 2018;45:20-30.

80. Joshi A, Roberts MJ, Perera M, et al. The clinical efficacy of PSMA PET/MRI in biochemically recurrent prostate cancer compared with standard of care imaging modalities and confirmatory histopathology: results of a single-centre, prospective clinical trial. Clin Exp Metastasis 2020;37:551-60.

81. García JR, Compte A, Buxeda M, et al. Value of 18F-Choline PET/MRI hybrid technique on the therapeutic approach for patients with prostate cancer treated with prostatectomy and rising prostate specific antigen levels below $1 \mathrm{ng} / \mathrm{ml}$. Rev Esp Med Nucl Imagen Mol (Engl Ed) 2020;39:197-203.

82. Gordon LG, Elliott TM, Joshi A, et al. Exploratory costeffectiveness analysis of 68Gallium-PSMA PET/MRIbased imaging in patients with biochemical recurrence of prostate cancer. Clin Exp Metastasis 2020;37:305-12.

83. Evangelista L, Zattoni F, Cassarino G, et al. PET/MRI in 
prostate cancer: a systematic review and meta-analysis. Eur J Nucl Med Mol Imaging 2021;48:859-73.

84. Chen Y, Pullambhatla M, Foss CA, et al. 2-(3-\{1-Carboxy5-[(6-[18F]fluoro-pyridine-3-carbonyl)-amino]-pentyl\}ureido)-pentanedioic acid, [18F]DCFPyL, a PSMA-based PET imaging agent for prostate cancer. Clin Cancer Res 2011;17:7645-53.

85. Ferguson S, Wuest M, Richter S, et al. A comparative

Cite this article as: Regmi SK, Sathianathen N, Stout TE, Konety BR. MRI/PET Imaging in elevated PSA and localized prostate cancer: a narrative review. Transl Androl Urol 2021;10(7):3117-3129. doi: 10.21037/tau-21-374
PET imaging study of 44gSc- and 68Ga-labeled bombesin antagonist BBN2 derivatives in breast and prostate cancer models. Nucl Med Biol 2020;90-91:74-83.

86. Minamimoto R, Hancock S, Schneider B, et al. Pilot Comparison of ${ }^{68} \mathrm{Ga}-\mathrm{RM} 2 \mathrm{PET}$ and ${ }^{68} \mathrm{Ga}$-PSMA-11 PET in Patients with Biochemically Recurrent Prostate Cancer. J Nucl Med 2016;57:557-62. 